\title{
Market Orientation and Business Performance among SMEs in Ghana
}

\author{
Mohammed Abdulai Mahmoud \\ Lecturer, Department of Marketing and Customer Management \\ University of Ghana Business School \\ University of Ghana \\ E-mail: amohammed@ug.edu.gh
}

\begin{abstract}
The effect of market orientation on business performance has been extensively researched over the past two decades with authors generally agreeing on its positive outcome. It appears however that previous studies placed much emphasis on its applications in large scale organizations. Only recently have researchers begun to publish articles on the patterns of market orientation in small and medium scale organizations (SMEs) (Blankson et al., 2006; Keskin, 2006). Even so, it seems that researchers are yet to reach a common ground on the appropriateness of this management toolkit to SMEs. This study argues that it is in this sector that firms need to be more customer focus, monitor competitive trends, and respond appropriately to market intelligence in order to survive given evidence of their financial, technical and other constraints. Following an adoption of two popular scales in the literature, the study investigated the market orientation-performance link among Ghanaian SMEs using a survey to collect data on 191 firms. Results show that the development of market orientation in this sector rests more on the attitude of owners/ managers and, more importantly, the repeatedly reported performance implication of market orientation does not elude Ghanaian SMEs. More specifically, market orientation leads to superior performance under ceaseless competitive conditions. Conclusions are drawn; the limitations and directions for further investigations of the construct are provided.
\end{abstract}

Keywords: Market orientation, Business Performance, SMEs, Ghana

\section{Introduction}

There abound numerous conceptual and empirical studies on the market orientation construct in the extant literature (see for review Kohli \& Jaworski, 1990; Narver \& Slater, 1990; Rueket, 1992; Jaworski \& Kohli, 1993; Greenley, 1995; Pitt et al., 1996; Appiah-Adu \& Ranchhod, 1998; Mahmoud et al., 2010). These works span from both developed (Harris, 2000; Esteban et al., 2001; Guo, 2002; Perry \& Shao, 2002; Elg, 2003; Green Jr. et al., 2005; Blankson et al., 2006; Keskin, 2006; Sen, 2006; Ozer et al., 2006; Low et al., 2007) and developing (Agarwal et al., 2003; Aggarwal \& Singh, 2004; Kuada \& Buatsi, 2005; Osuagwu, 2006; Dwairi et al., 2007; Hinson et al., 2008; Mahmoud et al., 2010) economies. The central argument of the developed and developing countries' studies demonstrates the indispensable role that market orientation plays in an organization's marketing activities in achieving superior performance in its chosen markets.

Moreover, literature on the impact of market orientation on firm performance has revealed mixed discoveries in the developed and developing countries studies (Narver \& Slater, 1990; Jaworski \& Kohli, 1993; Perry \& Shao, 2002 \& Dwairi et al., 2007). Studies conducted in the United States have demonstrated the positive effect of market orientation on performance whereas a mixed blessing of market orientation is reported among UK and other developing countries studies (Beamish et al., 1993; Pitt et al, 1996). There are also questions regarding the universal application of the market orientation construct by marketing scholars (Pelham \& Wilson, 1996). This stems from the fact that, there are differences in environments, industries and their structures as well as the size of firms (Pelham \& Wilson, 1996).

Following Blankson et al. (2006) and Keskin (2006), despite the attention devoted to market orientation by academics, research interest in market orientation within small and medium scale enterprises (SMEs) sector has been scanty (see also McLartey, 1998; Lee et al., 1999; Becherer et al., 2003). On the other hand, SMEs are vital in most economies including Ghana in that they contribute a lot in terms of GDP and employment (Abor and Beikpe, 2005 and Keskin, 2006). In the Ghanaian economy in particular, SMEs have been identified as the catalyst for the economic growth of the country as they make major contributions to employment generation and poverty reduction (Mensah, 2004; Abor and Beikpe, 2005). Thus, the SME sector is regarded in certain situations as a valve for absorbing the teeming unemployed youth in the Ghanaian economy (Mensah, 2004).

Adopting a market-orientated strategy is posited as a way of successfully managing the impact of changes in the SME domain. However, the application of market-orientation and its research models, which were developed for large-scale firms, may have different meanings in an SME context (Blankson et al., 2006; Keskin, 2006). This position is warranted given the fact that SMEs face peculiar problems including: deficiencies arising from their limited resources and range of technological competencies; influence of their owners/managers on the decision-making; dependence on 
small numbers of customers and suppliers; and focus on the efficiency of current operations, among others (Badger et al., 2001). The survival of SMEs has been the focus of a number of recent reports in Ghana, which call for new strategic directions if SMEs wish to sustain their competitiveness and financial success in the future (Ohene-Konadu, 2008).

However, there is lack of enough empirical and conceptual studies of market orientation and business performance among SMEs in Ghana. This may affect policy formulation and implementation in the SMEs domain. This is because the SMEs Owners and Managers may not appreciate the role of market orientation as a strategic tool for quality decision-making in the SME sector. This research attempts to address this gap and contribute to the literature by concentrating on the following research questions: what is the situation of market orientation among Ghanaian SMEs? Do antecedents of market orientation proposed by Jaworski and Kohli, 1993 impact on the SMEs market orientation levels and hence on performance in Ghana? Do environmental factors moderate the relationship between market orientation and business performance among the SMEs in Ghana? In the remainder of the discussions, this paper reviews the framework and theories underpinning market orientation leading to a number of research hypotheses. This is immediately followed by a detail specification of the research methodology. Thereafter, the empirical results are presented and discussed along with managerial implications. The final part of the paper presents some conclusions on the basis of the research findings, outlines some inherent limitations and provides some directions for future research.

\section{Literature review}

Market orientation is not a new concept in the marketing and management literature. Scholars argued that the postulation by Drucker (1954) that the customer must be the focus of organization's operations and the subsequent support given to this idea by Levitt (1960) that the customer is the reason for the organization's existence were all pointing to the fact that market orientation behavior was necessary at that time. This idea was extended to become known as the marketing concept (McNamara, 1972). Following these developments, the subject market orientation has received a great deal of attention from marketing scholars who have developed, tested and refined market orientation scales for measuring the degree of market orientation that organizations exhibit (see among others, Kohli and Jaworski, 1990; Narver and Slater, 1990; Heart and Diamantopoulos, 1993; Hooley et al., 1998; and Blankson \& Stokes, 2002).

While researchers have found congruence between market orientation and business performance (Blankson \& Stokes, 2002), there seems to be ambiguity as far as the appreciation as well as the adoption of the market orientation construct by SMEs is concerned (Harris, 1998; McLarty, 1998; Stokes, 2000). The position that market orientation has not been adopted by SMEs may have been supported by Stokes and Blackburn (1999) who contended that whereas traditional marketing concept is conceived of as a deliberate planned process which proceeds from a careful identification of market needs by formal research, and through purposeful development of new offerings to the market place, the small business deliberation involves informal, unplanned activity that relies on the intuition and energy of the owner/ manager to make things happen. Furthermore, following Stokes and Blackburn (1999), it appears that when compared to other functions of their business, SMEs owners have a problem with marketing; they appear to give marketing a low priority, often regarding marketing as "something that larger firms do". Meziou (1991) concurs that SMEs are more reluctant than larger firms to embrace the marketing concept in their strategy formulations. Apparently, SMEs do not conduct market research, and do not have long-term market planning (Peterson, 1988; Meziou, 1991; Blankson \& Stokes, 2002).

Supporting the foregoing, Harris (1998) in his study of small hotel businesses in the UK asserts that in reality the dimension of market orientation may not be applicable in the small business sector. The author noted that several key factors inhibit the ability of small businesses in focusing on trends and needs, or market orientation. These include: unclear view of the customer, commitment with the status quo, ignorance of market orientation, lack of competitive differentiation, limited resources, perceived inappropriateness and short-term focused. Also according to Carson (1993, cited in Blankson \& Stokes (2002), small firms embark upon marketing in such a general and inappropriate way that it does not appear to have any significant impact on performance and as a consequence is not perceived to be useful.

Although the foregoing may hold true for SMEs at large, following observations and recent developments in the Ghanaian SME sector, coupled with discussions with academics with expertise in SMEs and practitioners (owners/managers), it can be asserted that in view of the ongoing government support and concern for SMEs (Mensah, 2004), further research is needed to highlight the appreciation of marketing and it practices within the SME sector. Again, eventhough there are enough evidence that marketing is crucial to the survival and development of SMEs (Stokes and Blackburn, 1999), the fact that market orientation concept was developed largely from studies of large organizations makes it timely to examine the appropriateness of the construct to SMEs. A research in this order may reveal pertinent issues regarding marketing practices that should be of interest to policy makers, entrepreneurs and 
researchers interested in the SMEs sector. It must be noted here that Hills (1999) has observed that marketing and entrepreneurship largely determine the fate of entrepreneurs and SMEs around the world.

In Ghana, available data from the Registrar General indicates that $90 \%$ of companies registered are micro, small and medium enterprises. This target group has been identified as the catalyst for the economic growth of the country as they are a major source of income and employment. Data on this group is however not readily available. The Ministry of Trade and Industry (MOTI), in 1998 estimated that the Ghanaian private sector consists of approximately 80,000 registered limited companies and 220,000 registered partnerships from which they came out with the following definitions: micro enterprises-those employing up to 5 employees with fixed assets not exceeding the value of $\$ 10,000$; small enterprises-employ between 6 and 29 employees with fixed assets of $\$ 100,000$; and medium enterprises-employ between 30 and 99 employees with fixed assets of up to $\$ 1$ million. (Mensah, 2004).

\section{Theoretical framework}

A market-oriented firm is one which successfully applies the marketing concept (Kohli \& Jaworski, 1990; Pitt et al., 1996; Caruana et al., 1999). According to Blankson and Cheng (2005), the marketing concept holds that the key to organizational success is through the determination and satisfaction of the needs, wants and aspirations of target markets. They noted that these must be pursued more effectively and efficiently than that of competitors and with the intention of achieving profitability and or satisfying objectives. From the strategic marketing literature, market orientation involves the use of superior organizational skills in understanding and satisfying customers (Day, 1990). In essence, market orientation is derived from the application of marketing concept and it requires firms to monitor rapidly changing customer needs and wants, determine the impact of these changes on customer satisfaction, increase the rate of product innovation, and implement strategies that build the firms' competitive advantages.

There has been increased interest in the market orientation construct in the past two decades. Following this development, many attempts have been made by researchers to appreciate its make-up resulting in the operationalization of its definition as a construct (Blankson et al., 2006). Most definitions developed were derived from the conceptualization of both Kohli and Jaworski (1990) or Narver and Slater (1990). Kohli and Jaworski (1990) compared the three core elements of market orientation as a philosophy to the perception of marketing practitioners and observed that market orientation has three components: the organization-wide generalization of market intelligence pertaining to current and future customer needs; dissemination of the intelligence across departments; and organization-wide responsiveness to this intelligence. According to the authors, this is based on customers' opinion and it includes the consideration of: exogenous market factors that affect customer needs and performance; and current and future needs of customers (Kohli \& Jaworski, 1990). In the same fashion, Narver and Slater (1990) postulated that market orientation has three components namely: customer orientation, which involves understanding target customers and effectively deploying the skills and resources of the firm to satisfy customer by creating superior value; competitor orientation, which has to do with creating superior value through understanding the principal competitors' short-term strength and weaknesses and long-term capabilities and strategies; and inter-functional coordination, which involves getting all business functions working together to provide superior value (Narver \& Slater, 1990; Slater \& Narver, 1994).

Since market orientation is viewed as part of organizational culture (Narver \& Slater, 1990) or processes (Kohli \& Jaworski, 1990), it may be facilitated or hampered by internal factors (Jaworski \& Kohli, 1993; Harris, 2000; Harris \&Ogbonna, 2001). For this latter assertion, Kohli and Jaworski (1990) in their conceptual study proposed three categories of organizational factors (top management, interdepartmental dynamics and organizationwide systems) that determine the level of market orientation in any organization. The critical role of management in fostering a market orientation has appeared in several studies (Webster, 1988; Kohli \& Jaworski, 1990). These studies viewed management as highly influential on customer focus, interfunctional coordination and intelligence responsiveness. For instance, Kohli and Jaworski (1990, p. 7) state that "the commitment of top managers is an essential prerequisite to a market orientation". Thus, Harris and Ogbonna (2001) proclaimed that management behaviour is the key barrier to developing a market-oriented culture in an organization. Lear (1963, p.54) states that a market orientation, while 'better suited to the customer', creates complications in terms of structure. Ruekert (1992) analyzed organizational process as a barrier to market orientation and advised that the degree to which an organization can increase its market orientation is inextricably linked to the organizational structures, systems and processes created to sustain them. Briefly, certain characteristics of organizational structure such as low formalization and limited centralization facilitate the development of market orientation and vise versa (Jaworski \& Kohli, 1993). Related to this, Webster (1988) argued that the key to developing a market-driven, customer oriented business lies in how managers are evaluated and rewarded. Years later, Ruekert (1992, p. 238) substantiated Webster's (1988) argument when he finds that the extent of organizational market orientation is "positively associated with organizational practices in recruiting, training and rewarding of personnel". Additionally, several researchers have shown that the implementation of market orientation is greatly influenced by interdepartmental connectedness and conflict (Levitt, 1969 Jaworski \& Kohli, 
1993; Harris \& Piercy, 1999; Pulendran et al., 2000). Interdepartmental connectedness promotes interfunctional coordination leading to more frequent communication which is likely to enable the dissemination of collected market intelligence and facilitate a timely market focused response (Harris \& Piercy, 1999; Pulendran et al., 2000). On other hand, interdepartmental conflict inhibits communication across the departments of an organization, reducing interfunctional performance, and consequently inhibiting timely response to market needs which are in the core of the market orientation processes.

Indeed, market orientation has long been associated with higher result in terms of business profitability (Narver \& Slater, 1990) as well as success in the market place (Jaworski \& Kohli, 1993). Other studies have shown that market oriented organizations are likely to experience improved levels of employee satisfaction, esprit de corps and organizational commitment (Ruekert, 1992; Jaworski \& Kohli, 1993). However, there is recognition in literature that a firm may not reap the full benefits of market orientation in the presence of external factors such as decreasing competition, market stability, and turbulent technological conditions (Kohli \& Jaworski, 1990; Narver \& Slater, 1990; Jaworski \& Kohli, 1993; Slater \& Narver, 1994b). The main thrust of studies into the effect of external factors on the market orientation-performance relationship is that while external factors increase market uncertainties, the generation of, and response to, market intelligence are essentials to face market uncertainties. In this regard, research has shown that under circumstances of high market uncertainties, spending resources for market-oriented activities is worthwhile; but, under situations of stable market, technological and competitive environments, expending resources for market-oriented activities would be superfluous (Dwaire et al., 2007).

It appears that most studies focusing on market orientation were conducted in the developed western countries using data on large organizations. But the potential of SMEs, confronting many problems, to resist the implementation of the marketing concept were noted in the review. Given that it is ambiguous whether these market orientation frameworks developed largely through studies of large organizations from developed countries (Blankson \& Stokes, 2002; Keskin, 2006) are indeed applicable to SMEs, particularly those from developing countries, the model of the relationship between market orientation and its antecedents (or determinants) and consequences needs investigation in the SMEs sector. More specifically, a research in this order in Ghana is scant despite the increasing importance of SME in the Ghanaian economy. Building on this argument, the present study tests the applicability and the robustness of the market orientation model among Ghanaian SMEs following an adaptation of the Narver and Slater's (1990) and Jaworski and Kohli's (1993) frameworks as underpinned in Figure 1 (see appendix). The model is based upon the three research questions the study is set up to address.

\section{Methodology}

\subsection{Sampling the population}

The study employed a convenience sample of managers and business owners in the SME domain within the cities of Accra and Tema. The sample has been restricted to these two cities in view of the fact that most businesses in Ghana are situated within the two cities. This is in line with some studies that were conducted using a state (see Blankson \& Cheng, 2005; Blankson et al., 2006). The sample frame from which the population of SMEs is drawn was obtained from a database held by the National Board for Small Scale Industries (NBSSI) and the Association of Ghana Industries (AGI). These SMEs were operating in service and manufacturing. The final pool of SMEs to whom questionnaire were sent totaled 600 . Eventually, only 191 (constituting $31.83 \%$ response rate) useable questionnaires were returned by the respondents. After comparing the responses of the early and late respondents, on a number of characteristics, no significant different was found suggesting that the sample is free from response bias. The sample size and the response rate are consistent with related studies. For instance, Blankson and Cheng (2005) sampled 500 and had $21 \%$ response rate.

\subsection{Measurement of research constructs}

This study sought to assess the causal links between market orientation and business performance. Scale measures were adopted from both Narver and Slater (1990) and Jaworski and Kohli's (1993) constructs. The adoption of these two popular scales in a single study is not a new thing. For instance, Farrel and Oczkowski (1997) adopted the MKTOR (Narver and Slater's, 1990) and MARKOR (Kohli et al., 1993) measures in their study in Australia. Also, Hinson et al. (2008) adopted the two scales in their study of market orientation in Ghana. The questionnaire was divided into five different sections. Section one examine the market orientation of the sample. Section two addresses the antecedent to market orientation. The items under section three sought to measure some performance variables. Moderating factors were explored in section four and section five contains some control variables.

In line with Narver and Slater (1990), the market orientation scale was assigned 15 items and each was measured using a seven-point Likert type scale. Similarly, four performance variables were adopted from Narver and Slater's work and were measured with the aid of a five-point Likert type scale. Following Jaworski and Kohli (1993), the antecedent variables had 50 items and 17 items were assigned to the moderating variables. A five-point ranking scale was used in 
measuring both antecedent and moderating variables. To ensure the robustness of the business performance model, three items (size, age and sales turnover) were included as control variables in order to minimize specification bias.

\subsection{Reliability}

At this point it was a matter of necessity that reliability analysis was conducted on all the multi-items scales to check the internal consistency of the scales. This study adopted a cut off of 0.5 for cronbach's coefficient following Nunnally (1978). Using 0.5 as the cut off is not without precedent; it has been adopted in related studies (Blankson \& Stoke, 2002; Blankson \& Cheng, 2005). Reliability results have been presented in Table 1 below. Reliability test for performance, market orientation and centralization (alpha values of $0.838,0.871$ and 0.823 respectively) using the original number of items from the studies of Narver and Slater (1990) and Jaworski and Kohli (1993) resulted into higher degree of internal consistency of these scales. As for formalization, reward system, market turbulence and competitive intensity, the reliability test (alpha values of $0.685,0.695,0.562$ and 0.661 ) was relatively moderate, but acceptable since alpha value for each is well above the adopted cut-off point of 0.5 (Nunnally, 1978). In accordance with Hair et al. (1998), this is acceptable. On the contrary, the reliability test for management risk averse, inter-functional conflict, interconnectedness, top management emphasis, organizational commitment and technological turbulence scales using the original number of items from the original studies recorded weak and unacceptable values for cronbach's coefficient (values are below the 0.5 cut-off point).

To improve the internal consistency of these scales and to make them reliable for use in this study, one or two of the items were dropped. This resulted into better as well as acceptable values for cronbach's coefficient for most of these scales (see table 1). For example, using the original number of items reported in Jaworski and Kohli's (1993) study, the multi item scale "management risk averse" had cronbach's alpha of 0.447. After reducing the items from 6 to 5 , this value improved to 0.647 . These notwithstanding, interconnectedness and technological turbulence never generated acceptable cronbach's coefficients and as such have been dropped in the remainder of this analysis. Dropping a scale is not without precedent, Dwairi et al. (2007) in their study of market orientation in Jordan eliminated interdepartmental conflict because it had a low reliability coefficient. Accordingly, interdepartmental connectedness and technological turbulence are eliminated from further analysis in this current study.

\subsection{Models}

The three regression equations below were estimated to test the hypotheses.

$Y=\alpha+\beta_{1} M O+\beta_{2} S+\beta_{3} A+\beta_{4} S T+\varepsilon$ (1)

$M O=\alpha+\beta_{1} M R A+\beta_{2} I C F+\beta_{3} I C N+\beta_{4} F M+\beta_{5} C S+\beta_{6} R S+\beta_{7} T M E+\beta_{8} O r C+\varepsilon$

$Y=\alpha+\beta_{1} M O * M T+\beta_{2} M O * C I+\beta_{3} M O * T T+\varepsilon$

Note:

Y- Performance,

MO- Market orientation,

S- Size of the firm,

A -Age of the firm,

ST- Sales turnover,

MRA- Management risk aversion,

ICF- Inter-functional coordination,

ICN-Inter-functional conflict,

FM -formalization, CS -centralization,

RS- Reward system,

OrC- Organizational Commitment,

TME- Top Management Emphasis,

MO*MT-Market orientation x Market Turbulence,

$\mathrm{MO}^{*} \mathrm{CI}-$ Market orientation $\mathrm{x}$ Competitive Intensity,

$\beta$ - Coefficients, and

$\alpha$ - Constant. 


\section{Results and analysis}

\subsection{Demography}

It is witnessed from Table 2 that majority of SMEs are into services. In other words, while 57.61 percent of the sample is in the services sector, only 42.29 percent are in the manufacturing sector. This confirms the dominance of the service sector as far as SMEs in Ghana are concerned. The reported results also show that in terms of the type of product traded, overwhelming majority (about 78 percent) of SMEs trade in soft goods. This is not surprising in view of the fact that most hard goods are capital expenditure items requiring huge capital outlay which SMEs in themselves cannot raise.

It is observed that the sample is consistent with the literature's definition of Ghanaian SMEs. The reported result indicates an average number of employees of 49 (approximately) with the average dispersion around this value being steady at 15.33. According to Mensah (2004), Ghanaian SMEs employ between 6 and 99 workers. In this regard, the sample is largely consistent with the literature's definition of SMEs in Ghana. Furthermore, it was observed that, on the average, sampled SMEs have been in operation for about 16 years. With a relatively wide standard deviation of 19.47 , it can be asserted that the SME sector is still growing thereby highlighting the fact that the number of SMEs is increasing. Another important observation is that, on the average, change in sales turnover is recording increases annually across SMEs. With this observation, the significance of the SMEs sector in the Ghanaian economy in terms of income generation is reinforced. Put differently, income tax from SMEs could be increased annually due to increase in their annual sales assuming much of the increase is turned into operating income.

\subsection{Regression Analysis}

There is a significant positive relationship between market orientation and business performance $(\mathrm{r}=0.251, \mathrm{p} \leq 0.1)$. That is, to achieve superior outcome in business, SMEs' practitioners need to operate on customer lead approach, be competitor orientation, and strengthen inter-functional integration. Although this result was significant, it needs to be emphasized that size, age and sales turnover of the sample firms have some level of influences on their business performance (refer to Table 3 under appendix). They are however dropped from the remaining analysis since there were only used to avoid specification bias.

In Table 4, it is observed that top management risk aversion has a significant negative relationship with market orientation $(\mathrm{r}=-0.232$, at $p \leq .01)$. In other words, among the sampled SMEs, market oriented activities cannot be developed unless top management displays less risk-aversion behaviour. Therefore, for Ghanaian SMEs to become market oriented, the attitude of owner-managers must favour calculated risk-taking. Top management emphasis is found to be positively $(0.343)$ and significantly $(\mathrm{p} \leq .01)$ related to market orientation. This finding resonates Kohli and Jaworski‘s (1990); Jaworski and Kohli's (1993); Kuada and Buasti's (2005); and Dwaire et al.'s (2007) findings on this antecedent variable. Therefore, without the emphasis of owners/ managers it would be unlikely to commit necessary resources for SMEs to pursue market oriented activities. Owners/top managers shape the direction and values of their organizations (Webster, 1988); hence, owners/ managers of Ghanaian SMEs must provide the resources and strategic direction for SMEs to operate on market oriented principles.

It is observed (see Table 4) that the lesser the inter-functional conflict, the greater the market orientation of SMEs. That is, inter-functional conflict related negatively with market orientation. But this influence is never significant statistically. By implication, Ghanaian SMEs can have some wrangling yet market orientation will continue to grow, a finding that is inconsistent with the postulations in the literature (Kohli \& Jaworski, 1990). Similarly, reward system has no significant impact on the market orientation culture of SMEs. The analysis shows that market orientation tends to relate negatively, although insignificantly, with reward system $(\mathrm{r}=-0.121)$. With this kind of conflicting result, it is difficult to make any firm statement on the role of market-based reward system in the market orientation of the sample.

Furthermore, it is found that organizational commitment relates directly with market orientation ( $\mathrm{r}=0.029)$, highlighting that increased organizational commitment towards market oriented activities will increase the generation of, dissemination of, and response to, market intelligence among SMEs. But this relationship has no statistical significance perhaps an indication that small firms, in particular, need not have commitment from all workers to be market oriented. This may have reinforced the fact that general commitment needs to come from the owner/ manager, who is in most cases the "jack of all trade". Lastly, on the determinants of market orientation, the regression results provides a significant positive relationship between centralization and market orientation $(r=0.196, p \leq .05)$. In other words, centralized organizational structure is cherished among Ghanaian SMEs studied. While scholars (e.g. Ruekert, 1992; Webster, 1988) advocate that organizations must be less centralized to enhance market oriented cultures within, SMEs viewed centralization as crucial for the development and implementation of greater market orientation in their organizations. These results may not be surprising in that, for instance, the small business deliberation of the market place involves informal, unplanned activity that relies on the intuition and energy of the owner-manager to make things happen (Stokes \& Blackburn, 1999). 
Regression results in Table 5 also demonstrate that the Ghanaian business environment moderates the strength of the market orientation-performance relationship reported for the SMEs studied. In specific terms, the results suggest that the existence of strong competition leads to an even greater relationship between market orientation and performance of sampled SMEs $(\mathrm{r}=0.345)$. Similarly, stronger market turbulence in the SMEs sector generates stronger relationship between market orientation and performance of SMEs $(r=0.197)$. However, only the coefficient of the interacted market orientation-competitive intensity is significant at $\mathrm{p} \leq .1$. By implication, under condition of severe competition, the need for Ghanaian SMEs to be more market oriented becomes a key issue, as it provides a mean for firms to focus on activities that lead to the development quality products and service to enhance customer satisfaction and customer loyalty. Indeed, it is argued that in turbulent competitive markets, market orientation may be the saviour for stressed organizations (Harris \& Ogbonna, 2000). However, the results suggest that SMEs should be less customer focus where the market is witnessing high rate of change in the customer needs and preference, contradicting Kohli and Jaworski's (1990) proposition. This may be attributed to the fact that in Ghana, like in most developing African countries, demand for goods and services outstrips supply and customers preference, although changes in small units, does not dictate the way business is done, especially among Ghanaian SMEs who are noted for poor marketing skills (Mensah, 2004).

\section{Conclusions}

This study validates previous scholars' assertions about the relationship between market orientation and performance with a focus on the SMEs sector in Ghana. Despite the lack of agreement on the appropriateness of the market orientation construct developed and tested principally on studies of large firms to small and medium scale enterprises (SMEs), this study demonstrates that when applied by an SME, market orientation will positively influence its level of performance in business. That is the higher the level of market orientation, the greater the level of performance in Ghanaian SMEs, consistent with the overriding proposition of the literature that increased market orientation lead to higher firm performance (Narver \& Slater, 1990; Slater \& Narver, 1994; Agarwal et al., 2003; Green Jr. et al., 2005; Dwairi et al., 2007; Low et al., 2007).

In determining what factors would account for the market orientation of the Ghanaian SMEs internally, eight antecedents of market orientation were evaluated. While one of the variables (interconnectedness) could not be tested because the scale was very weak, four of the variables were supported and three unsupported. The results indicate that the power of top-management emphasis on market orientation is substantial across SMEs studied. Following Dwairi $e t$ al. (2007), all replications have been consistent with this relationship as such, top managements are crucial for Ghanaian SMEs to be market-oriented. Same can be said of management risk aversion, formalization and centralization; they pose considerable influence on market orientation behaviour of Ghanaian SMEs. However, as determinants of market orientation, organizational commitment, inter-functional conflict and reward system are not completely decisive. This study found these three to have no significant roles in the development of market orientation among the sampled Ghanaian SMEs.

Only two of the environmental factors were tested with technological turbulence dropped due to weakness in the scale. This study found that the degree of competition in the industry has substantial influence on the importance of market orientation to the performance of SMEs studied. On the other hand, similar to prior empirical studies (Kuada \& Buatsi, 2005; Dwairi et al., 2007), this study also found that eventhough market turbulence plays some role in the market orientation model, the nature of this role is not clear. For that matter, no firm conclusion can be drawn regarding how market turbulence would shape the importance of market orientation to Ghanaian SMEs.

Unlike a single industry analysis, the disadvantage of this multi-industry study is that the study lacks a focus on a single industry that could have provided a deeper knowledge and understanding of an industry's appreciation of market orientation and its relation to business performance. For future studies, a logical concentration on a single industry such as manufacturing or service might help to facilitate uniformly stronger support from management of the few SMEs in the industry, and to attain easy access to multiple, and knowledgeable raters within the few SMEs selected. Again, much emphasis was given to the external generalizability of the findings other than internal validity. For this reason, a large number of SMEs were sampled across different industries and this made it impossible to detail the investigation of each SME visited so that internal validity would not be overlooked much as we place emphasis on external generalizability. To deal with this, it is proposed that future research on this study may use multiple respondents from each SME. In this regard, researchers might segregate the target SMEs into their various industries. By this, objective correlates of market orientation would be developed and would increase confidence in the measures as well as reducing the concern about method variance, which accompanies most survey research.

\section{Acknowledgement}

The researcher would like to acknowledge the financial support toward this current study by the research and conferences committee of the University of Ghana Business School, University of Ghana, Legon, Accra, Ghana. 


\section{References}

Abor, J. and Biekpe, N. (2005). "Corporate Governance, Ownership Structure and Performance of SMEs in Ghana: Implications for Financing Opportunities", Corporate Governance, 7, 3, 288-300.

Agarwal, S., Erramill, M. and Dev, C. (2003). "Market orientation and performance in service firms: role of innovation", Journal of Services Marketing, 17, 1, 68-82.

Aggarwal, N. and Singh, R. (2004). "Market Orientation in Indian Organizations: An Empirical Study", Marketing Intelligence and Planning, 22, No.7, 700-715.

Appiah-Adu, K. and Ranchhod, A. (1998). "Market Orientation and Performance in the Biotechnology Industry: An Exploratory Empirical Analysis”, in Appiah-Adu (Ed) Strategic Orientation and Business Performance, 154-178, Graphic Packaging Limited, Ghana.

Badger, I.C., Mangles, T. and Sadler-Smith, E. (2001). “Organizational learning styles, competencies and learning systems in small, UK manufacturing firms", International Journal of Operations \& Production Management, 21, 1417-32.

Beamish, P., Craig, R. and McLellan, K. (1993). “The Performance Characteristics of Canadian versus UK Exporters in Small and Medium sized Firms", International Management Review, 33, 121-37.

Becherer, R. C., Halstead, D. and Haynes, P. (2003). "Marketing orientation in SMEs: effects of the internal environment", New England Journal of Entrepreneurship, 6, 1, 13-22.

Blankson, C. and Cheng, J.M.S. (2005). "Have small businesses adopted the market orientation concept? The case of small businesses in Michigan”, Journal of Business and Industrial Marketing, 20, 6, 317-30.

Blankson, C. and Stokes, D. (2002). "Marketing practices in the UK small business sector", Marketing Intelligence \& Planning, 20, 49-61.

Blankson, C., Motwani, J.G. and Levenburg, N.M. (2006). "Understanding the patterns of market orientation among small businesses", Marketing Intelligence and Planning, 24, 6, 572-590.

Carson, D. (1993). “A philosophy for marketing education in small firms”, Journal of Marketing Management, 9, 2,189-204.

Carson, W. and Gilmore, A. (2000). "SME marketing management competencies", International Business Review, 9 , 363-82.

Caruanna, A., Pitt, L. and Berthon, P. (1999). "Excellence-market oriented link: some consequences for service firms", Journal of Business Research, 44, 5-15.

Day, G.S. (1990). Market driven strategy; Processes for creating value. New York Free Press.

Drucker, P. (1954). "The Practice of Management”, Harper \& Row, New York, NY.

Dwairi, M., Bhuian, S. and Turkus, A. (2007). "Revisiting the pioneering market orientation model in an emerging economy", European Journal of Marketing, 41, 7/8, 713-721.

Elg, U. (2003). "Retail orientation: A preliminary framework", International Journal of Retail and Distribution Management, 31, 2,107 - 117.

Esteban, A., Millan, A., Molina A., and Martin-Consuegra, D., (2001). "Market Orientation in Service": A Review and Analysis", Journal of Marketing, 36, 9/10,1003-1021.

Farrell, M.A. and Oczkowski, E. (1997). "An analysis of the MKTOR and MARKOR measures of market orientation: an Austrailian perspective", Marketing Bulletin, 8, 30-40, available at: www.marketingbulleting.com or http://marketing-bulleting. Massey.ac.nz

Green, K. W. Jr., Inman, R. A., Brown G., and Wilis, T. H. (2005). "Market Orientation: Relation to Structure and Performance", Journal of Business \& Industrial Marketing, 20. 6, 276-84.

Greenley, G. E. (1995). "Market Orientation and Company Performance: Empirical. Evidence from UK Companies", British Journal of Management, 6, 1-13.

Guo, C. (2002). "Market orientation and business performance: A framework for service organizations", European Journal of Marketing, 36, 9/10,1154-1163.

Hair, J.F. Jr, Anderson, R.E., Tatham, R.L. and Black, W.C. (1998). Multivariate Data Analysis, 5th ed., Prentice-Hall, Englewood Cliffs, NJ. 
Harris, C. (2000). "The organizational barriers to developing market orientation" European Journal of Marketing, 34, 5/6, 598-624.

Harris, C. (1998). "The obstacle to developing market orientation: a study of small hotels", Proceedings of the Academy of Marketing Conference, Sheffield University, Sheffield, July 8-10, 612-3.

Harris, L.C. and Ogbonna, E. (2001) "Leadership Style and Market Orientation: An Empirical Study", European Journal of Marketing, 35, 5/6, 744-764.

Harris, L.C. and Piercy, N. (1999). "Management Behaviour and Barriers to Market Orientation in Retailing Companies", The Journal of Service Marketing, 13, 2, 113-131.

Heart, S. and Diamantopoulos, A. (1993)."Linking market orientation and company performance: preliminary work on Kohli and Jaworski's framework", Journal of Strategic Marketing, 1, 2, 93-122.

Hills, G.F. (1999). “An inaugural commentary for the Journal of Research in Marketing \& Entrepreneurship”, Journal of Marketing and entrepreneurship, 1, 1, 5-7.

Hinson, R., Kastner, A. Ofori, D and Mahmoud, A (2008). "Market Orientation and Export Performance; A Ghanaian Study", AJBER, 3, 2\&3, 62-91.

Hooley, G., Cox, T., Fahy, J., Shipley, D., Beracs, J., Fonfara, K. and Snoj, B. (1998). "Market Orientation in the transition economies of Central Europe", Procedings of the $27^{\text {th }}$ EMAC Conference, Track 5, Stockholm, May 20-23, 479-98.

Jaworski, B. and Kohli, A. (1993). "Market Orientation: Antecedents and Consequences", Journal of Marketing, 57, 53-70.

Keskin, H. (2006). "Market orientation, learning orientation, and innovation capabilities in SMEs: An extended model", European Journal of Innovation Management, 9, 4, 396-417.

Kohli, A. and Jaworski, B. (1990). "Market Orientation: The Construct, Research Propositions, and Managerial Implications", Journal of Marketing, 54, 2, 1-18.

Kuada, J. and Buatsi, S. (2005). "Market orientation and management practices in Ghanaian firms: Revisiting the Jarworski and Kohli framework", Journal of International Marketing, 13, 1, 58-73.

Lear, R.W. (1963). “No Easy Road to Market Orientation”, Harvard Business Review, 41, 5, 73-80.

Lee, K., Lim, S., Guan, H. and Tan, S.J. (1999). "Dealing with resource disadvantage: generic strategies for SMEs", Small Business Economics, 12, 4, 299-311.

Levitt, I. (1960). “Marketing Myopia”, Harvard Business Review, 38, 24-47.

Levitt, T. (1969). The Marketing Mode, McGraw-Hill, New York.

Low, R., Chapman, L. and Sloan, R., (2007). "Inter-relationship between innovation and market orientation in SMEs", Managerial Research News, 30, 12, 878-891.

Mahmoud, M.A., Kastner, A. and Yeboah, J. (2010). "Antecedents, environmental moderators and consequences of market orientation: A study of pharmaceutical firms in Ghana", Journal of Medical Marketing, 10, 3, 231-244.

McLartey, R. (1998). "Case study: evidence of a strategic marketing paradigm in a growing SME", Journal of Marketing Practice: Applied Marketing Science, 4, 4, 105-17.

McNamara, C.P. (1972). "The present status of the marketing concept", Journal of Marketing, 36, 1, 50-57.

Mensah, S. (2004). "A Review of SME Financing Schemes in Ghana”, A Presentation at the UNIDO Regional Workshop of Financing SMEs, Accra, Ghana, March 15-16.

Meziou, F. (1991). "Areas of strength and weakness in the adoption of the marketing concept by small manufacturing firms”, International Small Business Journal, 29, 72-8.

Narver, J. and Slater, S. (1990). "The Effect of Market Orientation on Business Profitability”, Journal of Marketing, 54, 4, 20-35.

Nunnally, J. (1978). Psychometric Theory, (2 ${ }^{\text {nd }}$ ed.). McGraw - Hill Publishing, New York.

Ohene-Konadu, N. (2008). "Northern Region gets \$119m support for SMEs”, Daily Graphic, Accra, Ghana, April 11.

Osuagwu, L. (2006). "Market Orientation in Nigerian Companies", Marketing Intelligence \& Planning, 24, 6, 608-631.

Ozer, A., Kocak, A. and Celik, O. (2006). "Determinants of market orientation in accounting firms", Marketing Intelligence and Planning, 24, 6, 591-607. 
Pelham, A. and Wilson, D. (1996). A Longitudinal Study of the Impact of Market Structure, Firm Structure, Strategy, and Market Orientation Culture on Dimensions of Performance" Journal of the Academy of Marketing Sciences, 24, 27-43.

Perry L. and Shao T. (2002). "Market Orientation and Incumbent Performance in dynamic Market" European Journal of Marketing, 36, 9/10, 1140-1153.

Peterson, R.T. (1988). "An analysis of new product ideas in small business", Journal of Small Business Management, 26, 25-31.

Pitt, L., Caruana, A. and Berthon, P. (1996). "Market Orientation and Business Performance: Some European Evidence, International Marketing Review, 13, 5-18.

Pulendran, S., Speed, R. and Widing II, R.E. (2000). "The Antecedents and Consequences of Market Orientation in Australia", Australian Journal of Management, 25, 2,119-144.

Ruekert, R. W. (1992). Developing a Market Orientation: An Organizational Strategy Perspective, International Journal of Research in Marketing, 9, 225-245.

Sen, B. (2006). "Defining market orientation for libraries", Library Management, 27, 4/5, 201-217.

Slater, S. and Narver, J. (1994). "Does Competitive Environment Moderate the Market Orientation Performance Relationship?”, Journal of Marketing, 58, 2, 46-55.

Stokes, D. (2000). "Entrepreneurship marketing: a conceptualization from qualitative research", Qualitative Market Research: An Internal Journal, 3,1,47-54.

Stokes, D. and Blackburn, R. (1999). "Entrepreneurship: building for the future”, Working Paper Series, Small Business Research Centre, Kingston University, UK.

Webster, F.E. (1988). "Rediscovering the Marketing Concept", Business Horizons, 31, 3, 29-39.

Table 1. Analysis of Internal Consistency

\begin{tabular}{|c|c|c|}
\hline Model & No. of Items & Cronbach's Alpha \\
\hline Performance & 5 & 0.838 \\
\hline Market Orientation & 15 & 0.871 \\
\hline Management Risk Averse & 5 & 0.647 \\
\hline Inter-functional Conflict & 5 & 0.712 \\
\hline Interconnectedness & 7 & 0.120 \\
\hline Formalisation & 7 & 0.685 \\
\hline Centralisation & 5 & 0.823 \\
\hline Reward System & 6 & 0.695 \\
\hline Top Management Emphasis & 3 & 0.623 \\
\hline Organisational Commitment & 5 & 0.534 \\
\hline Market Turbulence & 6 & 0.562 \\
\hline Competitor Intensity & 6 & 0.661 \\
\hline Technological Turbulence & 4 & 0.080 \\
\hline
\end{tabular}

Table 2. Demographic characteristics of the sample

\begin{tabular}{|l|c|c|c|c|}
\hline Item/Statistic & Frequency & Percentage (\%) & Mean & \\
\hline Type of Business & 78 & 42.39 & & \\
Manufacturing & 106 & 57.61 & & \\
Service & 184 & 100 & & \\
Total & 142 & 78.45 & & \\
\hline Type of Good & 39 & 21.55 & & \\
Soft & 100 & 100 & & \\
Hard & & & 48.69 & 15.36 \\
Total & & & 15.73 & 19.47 \\
\hline Size (S) & & & 2.78 & .53 \\
\hline Age (AG) & & & & \\
\hline Change in ST & &
\end{tabular}


Table 3. Regression coefficients for market orientation and performance.

\begin{tabular}{|l|l|}
\hline \multicolumn{2}{|l|}{ Dependent Variable } \\
\hline $\begin{array}{l}\text { Independent } \\
\text { Variable Performance }\end{array}$ \\
\hline Market Orientation & $0.251^{*}$ \\
\hline Size of Firm & $0.217(\mathrm{~ns})$ \\
\hline Sales Turnover & $0.140(\mathrm{~ns})$ \\
\hline Adjusted R2 & 0.086 \\
\hline $\mathrm{N}$ & 191 \\
\hline
\end{tabular}

${ }^{* * *} \mathrm{p} \leq .01,{ }^{* *} \mathrm{p} \leq .05,{ }^{*} \mathrm{p} \leq .1$, nsp value not significant

Table 4. Regression coefficients for the antecedents to market orientation.

\begin{tabular}{|l|c|}
\hline \multicolumn{2}{|c|}{ Dependent Variable } \\
\hline $\begin{array}{l}\text { Independent } \\
\text { Variable }\end{array}$ & $-0.232^{* * *}$ \\
\hline Management Risk Averse & $-0.058^{(\mathrm{ns})}$ \\
\hline Inter-functional Conflict & $0.265^{* * *}$ \\
\hline Formalization & $0.196^{* *}$ \\
\hline Centralization & $-0.121^{\text {(ns) }}$ \\
\hline Reward System & $0.343^{* * *}$ \\
\hline Top Management Emphasis & $0.029^{(\mathrm{ns})}$ \\
\hline Organisational Commitment & 0.456 \\
\hline Adjusted $\mathrm{R}^{2}$ & 191 \\
\hline $\mathrm{N}$ & \\
\hline
\end{tabular}

${ }^{* * *} p \leq .01,{ }^{* *} p \leq .05,{ }^{*} p \leq .1,{ }^{n s} p$ value not significant

Table 4. Regression coefficients for moderated market orientation-performance relationship.

\begin{tabular}{|l|c|}
\hline \multicolumn{2}{|c|}{ Dependent Variable } \\
\hline Independent Variable Performance & $0.345^{*}$ \\
\hline Market Orientation x Competitive Intensity & $0.197(\mathrm{~ns})$ \\
\hline Market Orientation x Market Turbulence & 0.209 \\
\hline Adjusted $\mathrm{R}^{2}$ & 191 \\
\hline $\mathrm{N}$ & \\
\hline
\end{tabular}

${ }^{* * *} p \leq .01,{ }^{* *} p \leq .05,{ }^{*} p \leq .1,{ }^{n s} p$ value not significant

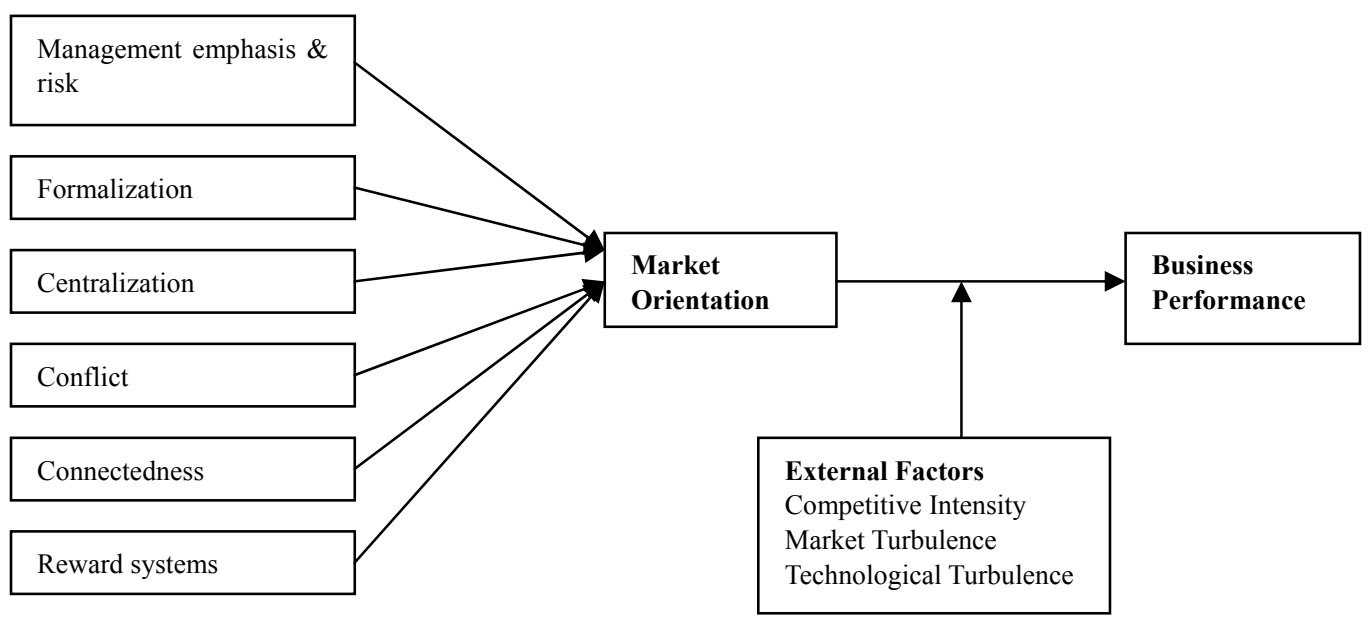

Figure 1. Conceptual Framework 